\title{
Type III coronary perforation during chronic total occlusion percutaneous coronary interventions treated with Cyanoacrylate glue embolization: case report and review of the technique
}

\author{
Carlo Tumscitz ${ }^{1}$, Valerio Lanzillotti ${ }^{2}$, Lucia Pirani ${ }^{3}$, Anna Maria Di Cesare $^{4}$, Alessandra Scoccia $^{4}$, \\ Francesco Gallo ${ }^{4}$ \\ ${ }^{1}$ Cardiology Unit, Azienda Ospedaliero Universitaria di Ferrara, Via Aldo Moro, Ferrara 44124, Italy. \\ ${ }^{2}$ Cardiology Unit, Ospedale Maggiore di Bologna, Largo Nigrisoli 2, Bologna 40133, Italy. \\ ${ }^{3}$ Cardiology Unit, Ospedale del Delta, Via Valle Oppio, 2, Lagosanto Ferrara 44023, Italy. \\ ${ }^{4}$ Cardiology Unit, Azienda Ospedaliero Universitaria di Ferrara, Via Aldo Moro, Ferrara 44124, Italy.
}

Correspondence to: Dr. Carlo Tumscitz, Cardiology Unit, Azienda Ospedaliero Universitaria di Ferrara, Via Aldo Moro, Ferrara 44124, Italy. E-mail: tumscitz@gmail.com

How to cite this article: Tumscitz C, Lanzillotti V, Pirani L, Di Cesare AM, Scoccia A, Gallo F. Type III coronary perforation during chronic total occlusion percutaneous coronary interventions treated with Cyanoacrylate glue embolization: case report and review of the technique. Vesse/ P/us 2019;3:20. http://dx.doi.org/10.20517/2574-1209.2018.71

Received: 8 Nov 2018 First Decision: 4 Mar 2019 Revised: 1 Apr 2019 Accepted: 22 May 2019 Published: 13 Jun 2019

Science Editor: Marouane Boukhris Copy Editor: Cai-Hong Wang Production Editor: Jing Yu

\begin{abstract}
In recent times the outcome of chronic total occlusion (CTO) percutaneous coronary interventions ( $\mathrm{PCl}$ ) in dedicated centers has steadily gained high success rate $(>80 \%)$ and low rate of coronary complications. Nevertheless comparing with non-CTO PCI the complications rate is higher, due to the higher lesion and technical complexity. Among the complications Type III coronary perforations remain the most troublesome events of CTO $\mathrm{PCl}$ and still carry a significant risk of death for the patients. The management of Type III coronary perforations has been extensively described as a flow chart of interventions and techniques to obtain rapid cessation of the blood extravasation and sealing of the ruptured vessel. Several techniques have been described to obtain bleeding cessation also in small vessel $(<2 \mathrm{~mm})$ perforations. In this paper we will describe two cases of CTO PCI with Type III small vessel coronary perforations treated with percutaneous Cyanoacrylate/(NBCA-MS)-based glue infusion through a conventional CTO microcatheter. This technique is fast and straightforward and can be applied to any conventional CTO microcatheter.
\end{abstract}

Keywords: Type III coronary perforations, coronary chronic total occlusion complication, cyanoacrylate/(NBCAMS)-based glue

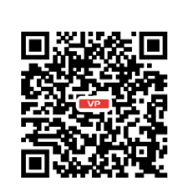




\section{INTRODUCTION}

Coronary chronic total occlusion (CTO) is characterized by heavy atherosclerotic plaque burden within the artery, resulting in complete occlusion of the vessel. Although the duration of the occlusion is difficult to determine, a coronary occlusion is defined as true CTO when the duration is at least 3 months or undetermined $^{[1]}$. Patients with CTO usually develop collaterals, which can be visualized through coronary angiography, from ipsilateral or contralateral vessel. However, these collaterals often do not provide sufficient blood flow to prevent myocardial ischemia during exercise and therefore anginal symptoms may appear ${ }^{[2]}$.

The incidence of CTO among patients who have a clinical indication for coronary angiography has been reported to be as high as $15 \%$ to $30 \%^{[3,4]}$.

The first important step made in CTO revascularization was to recanalize the occluded vessel using coronary collaterals. The septal channel has historically been the first described solution.The progressive improvement in the the technology of guidewires and microcatheters expanded the ability to cross different collateral channels even in very complex cases. Nowadays, examples of collaterals which can be used in CTO procedures, also include epicardial collaterals, even ipsilateral, and occluded saphenous grafts. Experienced operators are able to successfully treat very difficult CTO lesions using a combination of different pathways and techniques.

The results of older data registry (early CTO era) showed low success rate and higher MACE compared with non-CTO PCI, whereas CTO revascularization performed in experienced centers has now proven success rate up to $80 \%-90 \%$. On the other hand, due to the higher lesion and technical complexity, CTO complications rate has shown to be higher than non-CTO PCI $(1.6 \% v s .0 .8 \% ; P<0.0001)^{[5]}$.

Perforation is one of the most troublesome complications of CTO PCI. Despite the fact that coronary perforations are infrequent ( $0.33 \%$ of all cases) they are associated with poorer short- and long-term outcomes. In the British Cardiovascular Intervention Society Database CTO PCI was one of independent predictors of risk of perforation ${ }^{[6]}$.

Coronary artery perforations (CAP) are categorized according to Ellis classification as: Type I, extraluminal crater without extravasation; Type II, epicardial fat or myocardial blush without contrast jet extravasation; Type IIIa, extravasation through frank (>1 mm) perforation; Type IIIb "cavity spilling" (CS), which refers to perforations with contrast spilling directly into either the left ventricle, coronary sinus or other anatomic circulatory chamber $[\text { Table } 1]^{[7]}$. Grade I or II perforation are usually managed conservatively since they have a more benign clinical course. On the other hand, type III CAP was associated with a worse outcome. In earlier registers CAP Type III was associated with a very high in-hospital mortality rate (44\%), with the majority of patients requiring emergency surgery $(60 \%)^{[8]}$, while more recent data shows lower mortality rate $(15.2 \%)$ and lower rate of emergency surgery $(16 \%)^{[9]}$.

Among interventional collaterals suitable for CTO procedures, epicardial channels are considered the trickiest ones and appear more prone to perforation or rupture. This is caused by the relative high frequency of tortuosity and their small size (CC1 in Werner classification $)^{[10]}$. Perforation of epicardial channels carries a higher risk of cardiac tamponade and death when the treatment is delayed. This is due to the spillage of blood directly into the pericardial space.

The current endovascular treatment for perforated coronary arteries involves the use of prolonged balloon inflation and/or the use of covered stents (CS). The use of CS is feasible only when CAP is located in a large vessel due to the availability of CS starting just from a diameter of $2.25-2.5 \mathrm{~mm}^{[11]}$. Moreover, when collateral vessels emerge at a short distance from the CAP, the use of CS could lead to the occlusion of the collaterals and to the subsequent myocardial infarction. When CAP occurs in smaller vessels or collaterals $(<2 \mathrm{~mm})$, 
Table 1. Ellis classification of coronary artery perforations

\begin{tabular}{|c|c|c|c|c|}
\hline $\begin{array}{l}\text { ELLIS classification } \\
\text { Types }\end{array}$ & Ellis 1 & Ellis 2 & Ellis $3 a$ & Ellis $3 b$ \\
\hline Details & $\begin{array}{l}\text { Extraluminal } \\
\text { crater without } \\
\text { extravasation }\end{array}$ & $\begin{array}{l}\text { Epicardial fat or } \\
\text { myocardial blush } \\
\text { without contrast } \\
\text { jet extravasation }\end{array}$ & $\begin{array}{l}\text { Extravasation } \\
\text { through frank } \\
(>1 \mathrm{~mm}) \\
\text { perforation }\end{array}$ & $\begin{array}{l}\text { Perforations with contrast spilling } \\
\text { directly into either the left ventricle, } \\
\text { coronary sinus or other anatomic } \\
\text { circulatory chamber }\end{array}$ \\
\hline Mortality & $5.8 \%$ & $5.2 \%$ & $16.6 \%$ & $0 \%$ \\
\hline
\end{tabular}

various materials, such as autologous clots or fat ${ }^{[12,13]}$, gel foam ${ }^{[14]}$, fibrin glue ${ }^{[15]}$, microcoils ${ }^{[16]}$ and polyvinyl alcohol form ${ }^{[17-23]}$ can be embolized to the site in order to provide haemostasis and bleeding cessation.

When percutaneous treatment of CAP is not effective, surgical repair rapresent the bail out strategy. Efficacy of surgical repair however is not very high, as reported by a register from Al-Lamee et al..$^{[9]}$, where the rate of success was just $44.4 \%$.

In this case report we used (NBCA-MS)-based glue embolization (GLUBRAN2, GEM s.r.l. ITALY) in order to seal the perforation of small vessels during retrograde and antegrade revascularization of two cases of CTO-PCI.

Sterile glue is available for medical use either as pure synthetic glue (Histoacryl), or as dual component fibrin glue (fibrin plus thrombin). Sterile glue has been described as an effective embolization material for neurointerventional indications ${ }^{[24,25]}$, closure of oesophageal varices ${ }^{[26]}$, femoral pseudoaneurysms $s^{[27]}$, septal ablation in Hypertrophic Obstructive Cardiomyopathy ${ }^{[28]}$ and as a surgical adjunctive tool to stick a patch over the myocardial wall after an acute myocardial infarction complicated with cardiac rupture ${ }^{[2,30]}$. The use of sterile glue has already been described for the embolization of the right coronary artery's distal portion ${ }^{[31]}$.

The (NBCA-MS)-based glue can be injected pure or pre-mixed with Ethiodized oil (Lipiodol/Ethiodol). The mechanism of the (NBCA-MS)-based glue is related to his reaction to Na ions of tissue fluids. When (NBCAMS)-based glue comes into contact with $\mathrm{Na}$ ions the glue solidifies in a variable amount of time which varies from a few seconds to one minute depending on the proportion of Ethiodized oil you pre-mix with [Table 2]. Ethiodized oil also works as a Contrast agent which produces radiopacity in the mixture and helps the physician to confirm the site of embolization. Na ions are also present in Heparin and in Contrast media therefore both sterile cup and the syringes used for mixing the components shouldn't have been in contact with blood and Heparin. Furthermore, the microcatheter should be carefully flushed with dextrose solution just before the injection of the (NBCA-MS)-based (pure or mixture) in order to clean the inner surface from blood or heparin residues. This flushing avoids the premature start of the glue polymerization process into the microcatheter, which could occlude it totally or partially and make the microcatheter useless for multiple injections.

The injection can be done in a "single shot" fashion or with multiple "sandwich" injections when the mixture is alternated with dextrose boluses.

Choosing the best proportion of ethiodized oil and the right amount of mixture is of paramount importance to achieve the best results. The proportion of (NBCA-MS)-based with ethiodized oil component in very small leakage of distal perforations can be 1:1 or 2:1 with a "single shot" 0.5-1 mL bolus. This strategy allows fast and effective sealing with the same microcatheter already in place. In case of a bigger leak when the perforation is more proximal or if there are other branches very close to the perforation site the multiple "sandwich" technique with (NBCA-MS)-based/ethiodized oil proportion of 1:2 to 1:4 with small boluses of 0.3-0.5 mL allows more precise embolization with smaller risk of back flow of the mixture which could cause side branch occlusion or thrombosis. After last embolization it is always advisable to perform a rapid 
Table 2. Polymerization time based on the proportion of Lipidiol into the mixture (Ethiodized oil: Cyanoakrylate glue)

\begin{tabular}{lcccccc}
\hline & Ethiodized oil 1:1 & Ethiodized oil 2:1 & Ethiodized oil 3:1 & Ethiodized oil 4:1 & Ethiodized oil 5:1 & Ethiodized oil 6:1 \\
\hline Start polymerization & $5 \mathrm{sec}$ & $10 \mathrm{sec}$ & $10 \mathrm{sec}$ & $18 \mathrm{sec}$ & $20 \mathrm{sec}$ & $25 \mathrm{sec}$ \\
End polymerization & $40 \mathrm{sec}$ & $60 \mathrm{sec}$ & $75 \mathrm{sec}$ & $85 \mathrm{sec}$ & $110 \mathrm{sec}$ & $120 \mathrm{sec}$ \\
\hline
\end{tabular}

pull-back of the microcatheter ("hit and run") considering that the glue could solidify in the distal tip of the microcatheter or trap it into the coronary system.

\section{CASE REPORT}

The first patient is a 78-year old male with stable angina Canadian Class Society ${ }^{[3]}$. He was admitted 1 month earlier for stable angina and the coronary angiography showed a severe coronary artery disease with critical stenosis of left anterior descending artery (LAD) and left circumflex artery (LCX) and a CTO of the right coronary artery (RCA) [Figure 1A]. The case was discussed in Heart Team and surgical revascularization was excluded by patient's preference.

After revascularization of the LAD and LCX, revascularization of the CTO of RCA was staged after 1 month.

JCTO score of the RCA CTO was 3 and the most appealing interventional collateral from LAD to RCA was a septal branch and a very tortuous epicardial vessel from distal LAD [Figure 1B]. After several unsuccessful attempts to advance the guidewire on the septal, we managed to cross the epicardial vessel with regular SION guidewire (Asahi Intecc). The guidewire successfully crossed the most tortuous section of the channel but it was unable to progress further for lack of support from the microcatheter which was stocked at the entry point of the epicardial channel. We tried to rotate and push the Corsair microcatheter (Asahi Intecc) in order to advance closer to the guidewire's tip [Figure 1-C], but during the manipulation the catheter suddenly stepped forward out of the vessel and a type 3 perforation occurred [Figure 1D]. After confirming the site of the coronary rupture, we placed the microcatheter $10-20 \mathrm{~mm}$ proximal to the perforation. Promptly a Ethiodized oil and Glubran mixture (1:1 ratio) was prepared. After flushing the microcatheter with a dextrose solution, the mixture was injected into the distal LAD [Figure 1E]. After 10-15 seconds cessation of the bleeding extravasation was observed [Figure $1 \mathrm{~F}$ ]. The patient remained stable and asymptomatic. No significant pericardial effusion was observed after several echocardiographic exams. The patient was discharged after 7 days. A new attempt of the recanalization is planned in the next few months.

The second patient is a 82 -year old female affected by arterial hypertension, dyslipidaemia and mild carotid atherosclerosis. The patient had no cardiovascular history; she complained of effort dyspnoea and legs oedema. At the Echocardiography we observed a dilatation of the left ventricle with diffuse hypokinesia and moderate impairment of the ejection fraction (EF 40\%) and moderate functional mitral regurgitation. Because of the new onset of heart failure, we planned a coronary angiography. The angiography showed a severe, calcific tri-vessel coronary disease, involving the left main and proximal LAD, and a total occlusion of the mid LAD and RCA [Figure 2A]. During the Heart Team discussion, the patient was refused from the cardiac surgeon because of advanced age and frailty and a complete percutaneous revascularization was planned.The CTO of the RCA was short and a visible microchannel seemed to give a good chance to cross with sliding technique. Thus, we decided to perform recanalization of RCA first, with antegrade approach avoiding double access due to absence of coronary collaterals from left coronary system and severe left main disease. We readly crossed the lesion with a soft polymeric guidewire Fielder XT-R (Asahi intecc), [Figure $2 \mathrm{~B}$ ]. After reaching the distal vessel and confirming the position of the wire with multiple projections we performed several dilatations with small compliant balloons. After dilatation, we observed a severe perforation of the posterior-lateral branch, probably due to the guidewire positioned distally in a smaller branch [Figure 2C]. We planned to implant a covered stent crossing and covering the small branch 

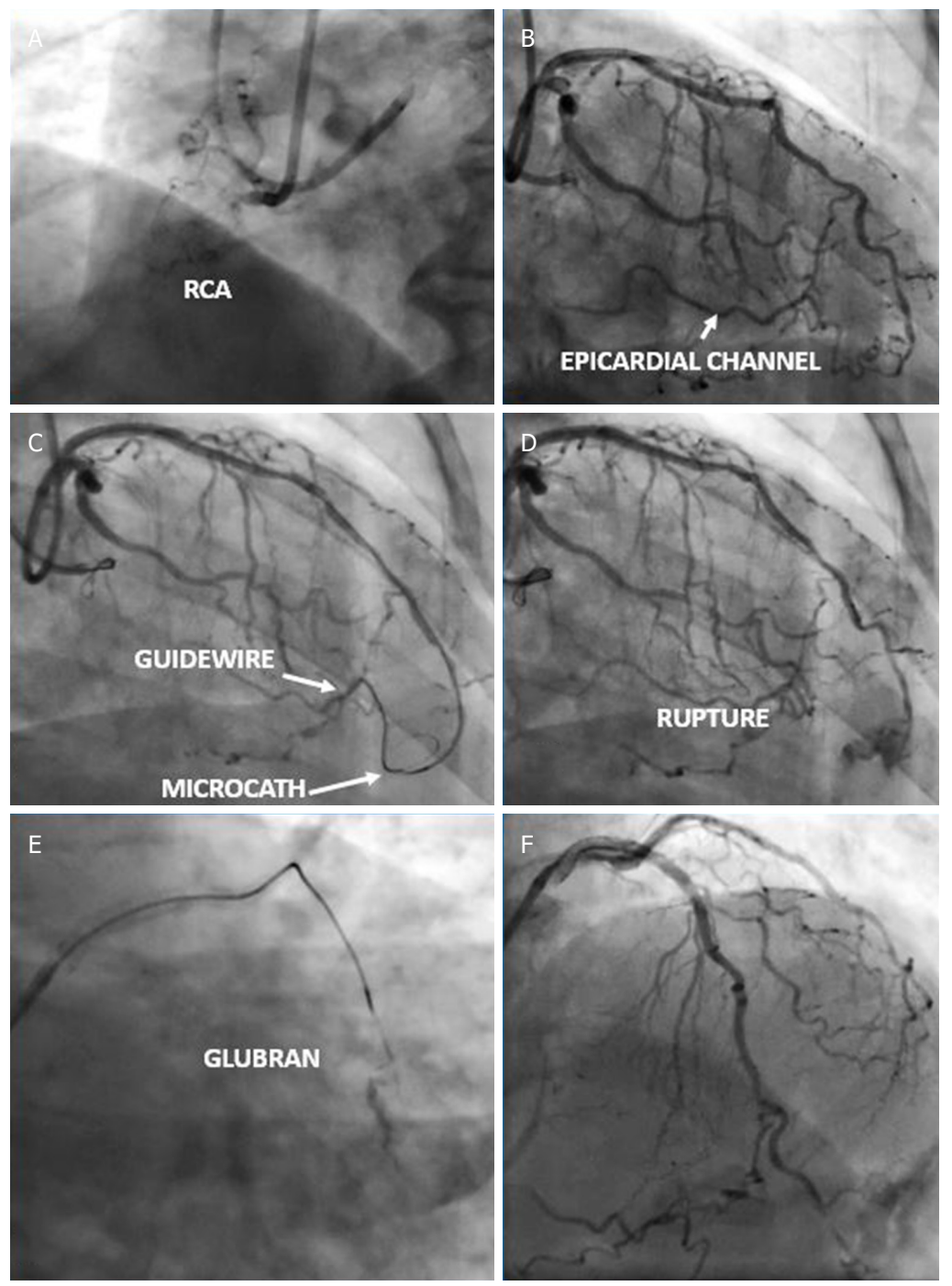

Figure 1. First case presented. $A$ : lesion at RCA; occluded at proximal portion; $B$ : epicardial channels from LAD to RCA; C: Guidewire into the epicardial channel; D: Evidence of extra vasal bleeding from distal LAD; E: (NBCA-MS)-based glue injection; F: Final result

involved in the coronary rupture. Because the patient was stable and the vessel was diffusely calcified and narrowed, we decided to perform PTCA and stenting of the RCA proximally to the rupture in order to facilitate the CS progression. After 2 long DES implantation $(3 \mathrm{~mm} \times 28 \mathrm{~mm}$ and $3 \mathrm{~mm} \times 40 \mathrm{~mm})$, a lowprofile CS (Aneugraft) it was not able to advance in the posterior descending artery (PDA) more than just at the origin of the vessel and we decided to deploy it there. Nevertheless the postero-lateral (PL) branch was still patent and at the angiography the bleeding extravasation was still present [Figure 2D]. We eventually decided to wire the small branch, advance a microcatheter and perform an embolization with (NBCA-MS)based glue [Figure 2E]. After mixing Lipidiol and (NBCA-MS)-based glue (3:1), the mixture was injected through a microcatheter Finecross (Terumo, Japan) using the "sandwich" technique for 3 overall "shots". In the last angiographic control, the rupture appeared closed and the bleeding stopped [Figure 2F]. The RCA and posterior descending showed a final TIMI 3 flow. We concluded the procedure with a PCI and 2 drug eluting stent (DES) implantation on left main artery to LAD-LCX (LM-LAD-LCX) bifurcation with a double kissing (DK) crush technique and CTO-PCI of LAD and LCX was planned as a staged procedure. 

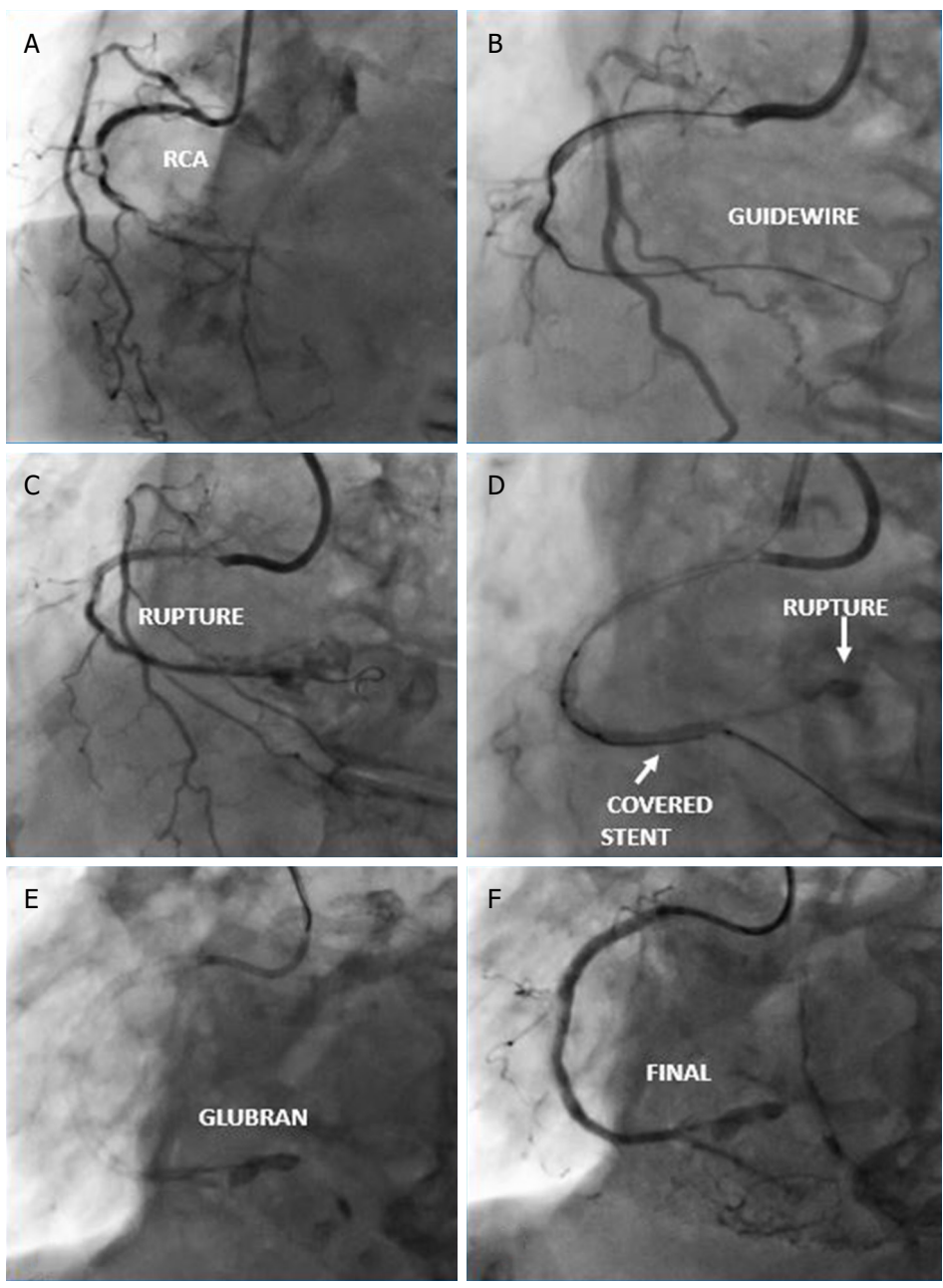

Figure 2. Second case presented. A: CTO of the RCA (Antegrade injection); B: Guidewire in the PL branch after crossing the CTO lesion; C: Evidence of extravasal bleeding at the level of the PL branch; D: persistence of extravasal bleeding at the distal edge of the covered stent; $\mathrm{E}$ : (NBCA-MS)-based glue injection; F: Final result. CTO: chronic total occlusion

\section{DISCUSSION}

Coil embolization for the treatment of small vessel Ellis type III perforations is considered the gold standard for emergent sealing. CTO operators always keep a set of different coils ready in the catheterization laboratory and should know the compatibility of the coils with different microcatheters used for CTO PCI ${ }^{[32]}$. Ideally, coils should be delivered in every CTO microcatheter but this is not always true. Moreover, sealing perforations with coils can be time-consuming and significantly costly when multiple coils are needed. On the other hand, auxiliary embolization material such as subcutaneous fat tissue or clots or trombin, are troublesome and inconvenient to prepare and are not adequately precise and reliable to deliver. For these reasons we believe that (NBCA-MS)-based glue should be an effective and inexpensive tool to keep in every catheterization laboratory as an alternative to the embolization coils.

On the other hand, the use of (NBCA-MS)-based glue compared with coils requires some experience to be delivered in a precise and safe manner. The adverse events described after glue embolization are basically divided in three main categories: inadvertent vascular embolization, suboptimal agent polymerization time, and catheter retention ${ }^{[33]}$. Both the suboptimal agent polymerization time and the catheter retention are related to the operator's inexperience. Correct proportion of the mixture (NBCA-MS)-based glue/ethiodized oil and use of small boluses or sandwich technique make the procedure safer and keep such complications infrequent. 
On the other hand when the bleeding site is very close to major branches, coiling is always preferable because risk of inadvertent vascular embolization is not negligible, though coiling is definitely more onerous and time-consuming ${ }^{[34,35]}$.

Another point in favor of (NBCA-MS)-based glue is his ability to create a sort of wide patch of polymeric material around the rupture that can cover different size of coronary perforations. This could be of adjunctive help in epicardial perforations when coiling from one side of the collateral could be not enough to stop the bleeding, and coiling from the other side could be troublesome if the CTO is not recanalized. The mechanism of the sealing in this setting could be explained with formation of aggregates of chain growth polymers in the tissue around the spillage, along with the obstruction of the afferent vessel.

Interestingly no tissue adverse reactions was described after embolization despite the wide spectrum of medical use of (NBCA-MS)-based glue.

\section{DECLARATIONS}

Authors' contributions

All authors contributed to the manuscript.

\section{Availability of data and materials}

Not applicable.

\section{Financial support and sponsorship}

None.

\section{Conflicts of interest}

All authors declared that there are no conflicts of interests.

\section{Ethical approval and consent to participate}

Not applicable.

\section{Consent for publication}

Not applicable.

\section{Copyright}

(c) The Author(s) 2019.

\section{REFERENCES}

1. Stone GW, Kandzari DE, Mehran R, Colombo A, Schwartz RS, et al. Percutaneous recanalization of chronically occluded coronary arteries: a consensus document: part I. Circulation 2005;112:2364-72.

2. Sachdeva R, Agrawal M, Flynn SE, Werner GS, Uretsky BF. The myocardium supplied by a chronic total occlusion is a persistently ischemic zone.Catheter Cardiovasc Interv 2014;83:9-16.

3. Kahn JK. Angiographic suitability of catheter revascularization of total coronary occlusions in patients from a community hospital setting. Am Heart J 1993;126:561-4.

4. ChristoffersonRD. Effect of chronic total coronary occlusion on treatment strategy. Am J Cardiol 2005;95:1088-91.

5. Brilakis ES, Banerjee S, Karmpaliotis D, Lombardi WL, Tsai TT, et al. Procedural outcomes of chronic total occlusion percutaneous coronary intervention: a report from the NCDR (National Cardiovascular Data Registry). JACC Cardiovasc Interv 2015;8:245-53.

6. Kinnaird T, Kwok CS, Kontopantelis E, Ossei-Gerning N, Ludman P, et al. Incidence, determinants, and outcomes of coronary perforation during percutaneous coronary intervention in the United Kingdom between 2006 and 2013 : an analysis of 527121 cases from the British Cardiovascular Intervention Society Database. Circ Cardiovasc Interv 2016;9:e003449.

7. S.G. Ellis, S. Ajluni, A.Z. Arnold, et al. Increased coronary perforation in the new device era. Incidence, classification, management, 
and outcome. Circulation,1994;90:2725-30.

8. Javaid A, Buch AN, Satler LF, Kent KM, Suddath WO, et al. Management and outcomes of coronary artery perforation during percutaneous coronary intervention. Am J Cardiol 2006;98:911-4.

9. Al-Lamee R, Ielasi A, Latib A, Godino C, Ferraro M, et al. Incidence, predictors, management, immediate and long-term outcomes following grade III coronary perforation. JACC Cardiovasc Interv 2011;4:87-95.

10. Werner GS, Ferrari M, Heinke S, Kuethe F, Surber R, Richartz BM, et al. Angiographic assessment of collateral connections in comparison with invasively determined collateral function in chronic coronary occlusions. Circulation 2003;107:1972-7.

11. Kilic ID, Fabris E, Serdoz R, Caiazzo G, Foin N, et al. Coronary covered stents. EuroIntervention;12:1288-95.

12. Hadjimiltiades S, Paraskevaides S, Kazinakis G, Louridas G. Coronary vessel perforation during balloon angioplasty: a case report. Cathet Cardiovasc Diagn 1998;45:417-20.

13. Komatsu I, Hirano K, Takimura H, Araki M, Yamawaki M, et al. A case of coronary artery perforation with successful hemostasis using over-the-wire balloon and autologous blood perfusion. Cardiovasc Interv Ther 2013;28:197-201.

14. Dixon SR, Webster MW, Ormiston JA, Wattie WJ, Hammett CJ. Gelfoam embolization of a distal coronary artery guidewire perforation. Catheter Cardiovasc Interv 2000;49:214-7.

15. Sto" rger H, Ruef J. Closure of guide wire-induced coronary artery perforation with a two-component fibrin glue. Catheter Cardiovasc Interv 2007;70:237-40.

16. Gaxiola E, Browne KF. Coronary artery perforation repair using microcoil embolization. Cathet Cardiovasc Diagn1998;43:474-6.

17. Albiero R, Nishida T, Corvaja N, Vaghetti M, Di Mario C, et al. Left internal mammary artery graft perforation repair using polytetrafluoroethylene -covered stents. Cathet Cardiovasc Intervent 2000;51:78-82.

18. Mahmud E, Douglas JS. Coil embolization for successful treatment of perforation of chronically occluded proximal coronary artery. Cathet Cardiovasc Intervent 2001;53:549-52.

19. Assali AR, Moustapha A, Sdringola S, Rihner M, Smalling RW. Successful treatment of coronary artery perforation in an abciximabtreated patient by microcoil embolization. Catheter Cardiovasc Interv 2000;51:487-9.

20. Aslam MS, Messersmith RN, Gilbert J, Lakier JB. Successful management of coronary artery perforation with helical platinum microcoil embolization. Cathet Cardiovasc Intervent 2000;51:320-2.

21. Dixon SR, Webster MWI, Ormiston JA, Wattie WJ, Hammett CJK. Gelfoam embolization of a distal coronary artery guidewire perforation. Cathet Cardiovasc Intervent 2000;49:214-7.

22. Yoo B, Yoon J, Lee SH, Kim JY, Lee HH, et al. Guidewire-induced coronary artery perforation treated with transcatheter injection of polyvinyl alcohol foam. Cathet Cardiovasc Intervent 2001;52:231-4.

23. Alfonso F, Goicolea J, Herna'ndez R, Ferna'ndez-Ortiz A, Segovia J, et al. Arterial perforation during optimization of coronary stents using high-pressure ballon inflations. Am J Cardiol 1996;78:1169-72.

24. Teng MM, Chen CC, Lirng JF, Chen SS, Lee LS, et al. N-butyl-2- (NBCA-MS)-based for embolization of carotid aneurysm. Neuroradiology 1994;36:144-7

25. Luo CB, Teng MM, Chang FC, Chang CY. Transarterial balloon-assisted n-butyl-2- (NBCA-MS)-based embolization of direct carotid cavernous fistulas. AJNR Am J Neuroradiol 2006;27:1535-40.

26. Romero-Castro R, Pellicer-Bautista FJ, Jimenez-Saenz M, Marcos-Sanchez F, Caunedo-Alvarez A, et al. EUS-Guided injection of (NBCA-MS)-based in perforating feeding veins of gastric varices: Results in 5 cases. Gastrointest Endosc 2007;66:402-7.

27. Goel PK, Modi N, Baijal SS, Kathuria M, Agrawal SK. Sonographically guided thrombin injection for the treatment of femoral artery pseudoaneurysm. Indian Heart J 2003;55:365-7.

28. Olivari Z, Rubartelli P, Piscione F, Ettori F, Fontanelli A, et al. Immediate results and one-year clinical outcome after percutaneous coronary interventions in chronic total occlusions: data from a multicenter, prospective, observational study (TOAST-GISE). J Am Coll Cardiol 2003;41:1672-8.

29. Terashima M, Fujiwara S, Yaginuma GY, Takizawa K, Kaneko U, et al. Outcome of percutaneous intrapericardial fibrin-glue injection therapy for left ventricular free wall rupture secondary to acute myocardial infarction. Am J Cardiol 2008;101:419-21.

30. Fujimatsu T, Oosawa H, Takai F, Aruga M, Ogiwara F, et al. Patch-and-glue sutureless repair for blowout rupture after myocardial infarction: report of 2 cases. Ann Thorac Cardiovasc Surg 2008;14:48-51

31. Goel PK. Delayed and repeated cardiac tamponade following microleak in RCA successfully treated with intra-arterial sterile glue injection. Catheter Cardiovasc Interv 2009;73:797-800.

32. Gasparini GL, Merella P, Mazzarotto P, Gagnor A, Garbo R, et al. Retrograde approach-related epicardial collateral channel perforation successfully treated with simultaneous bilateral coils embolization: a case illustration and review. Cardiovasc Revasc Med 2018;19:87986.

33. Hannah Hill, Jeffrey Forris Beecham Chick, Anthony Hage, Ravi N. Srinivasa. N-butyl cyanoacrylate embolotherapy: techniques, complications, and management. Diagn Interv Radiol. 2018;24:98-103.

34. Kakaei F, Seyyed Sadeghi MS, Sanei B, Hashemzadeh S, Habibzadeh. A randomized clinical trial comparing the effect of different haemostatic agents for haemostasis of the liver after hepatic resection. HPB Surg 2013;2013:587608.

35. Arvin R. Wali, Charlie C. Park, David R. Santiago-Dieppa, Florin Vaida, James D. Murphy, et al. Pipeline embolization device versus coiling for the treatment of large and giant unruptured intracranial aneurysms: a cost-effectiveness analysis. Neurosurg Focus 2017;42:E6. 